\title{
First Reported Cases of Urinary Myiasis in Iraq
}

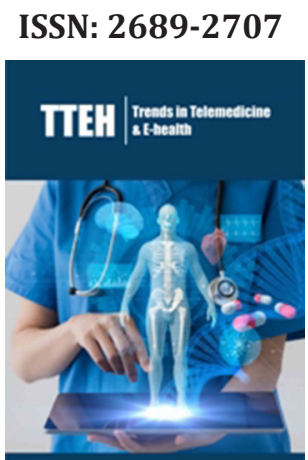

*Corresponding author: Mohammed B Ismail, Department of Urology (CABMS), College of medicine, Iraq

Submission: 海眥 February 8, 2020

Published: 㑑 March 17, 2020

Volume 2 - Issue 3

How to cite this article: Raghib JH Alshimmre, Mohammed B Ismail. First Reported Cases of Urinary Myiasis in Iraq. Trends Telemed E-Health 2(3). TTEH. 000538. 2020. DOI: 10.31031/TTEH.2020.02.000538

Copyright@ Mohammed B Ismail, This article is distributed under the terms of the Creative Commons Attribution 4.0 International License, which permits unrestricted use and redistribution provided that the original author and source are credited.

\author{
Raghib JH Alshimmre ${ }^{2}$ and Mohammed B Ismail ${ }^{1 *}$ \\ ${ }^{1}$ Department of Urology (CABMS), Iraq \\ ${ }^{2}$ Department of Urology (FICMS), Iraq
}

\section{Abstract}

Myiasis is theinfestation by larvae of flies. Myiasis mayinvolve the skin, eyes, nasal passages, gastrointestinal and genitourinary tracts. Cases of urinary myiasis are very rare mostly occurs in immunocompromised hosts, those with previous urologic instrumentation or those with poor socioeconomic status. We present a case of successful outpatient treatment of urinary myiasis in two immunocompetent females without prior urological history.

\section{Introduction}

Myiasis is defined as invasion of the body by the larvae of flies, characterized as cutaneous (subdermal tissue), gastrointestinal, nasopharyngeal, ocular, or urinary, depending on the region invaded [1]. Any infection due to invasion of tissues or cavities of the body by larvae of dipterous insects [2]. The disease occurs predominantly in rural areas and is associated with poor hygienic practices. Myiasis producers can be divided into three classes:

A. Obligate parasites requiring living tissue for larval development.

B. Facultative parasites whose larvae usually develop on carrion but may invade wounds and

C. Accidental myiasis [3]-which commonly is enteric, resulting from swallowing eggs or larvae with one's food, i.e. pseudomyiasis can happen when eggs or larvae are accidentally deposited on oral or genitourinary opening.

\section{Classification}

A. The classical description of myiasis is according to the part of the host that is infected. This is the classification used by ICD-10 [4]. For example:
a. Cutaneous (B87.0)
b. Nasopharyngeal nose, sinuses or pharynx. (B87.3)
c. Ophthalmic or ocular in or about the eye (B87.2)
d. Auricular in or about the ear (B87.4)

e. Gastric, rectal, or intestinal/enteric for the appropriate part of the digestive system (B87.82)

f. Urogenital (B87.81).

B. Another aspect is the relationship between the host and the parasite and provides insight into the biology of the fly species causing the myiasis and its likely effect. Therefore, the myiasis is described as either [4].

a. Obligatory, where the parasite cannot complete its life cycle without its parasitic phase, which may be specific, semi specific, or opportunistic.

b. Facultative, incidental, or accidental, where it is not essential to the life cycle of the parasite; perhaps a normally free-living larva accidentally gained entrance to the host [5]. 


\section{Case Report}

Two females aged 34 and married, and a fifteen-year-old complained about the passage of worms in urine intermittently during the last $t$ weeks on Spring 2017. They were in good health and non-diabetic nor having chronic illnesses. In addition, they reported mild dysuria, no fever and no itching. The urinalysis test showed 4 to 7 pus cells Per High Power Field (PHF), no significant Red Blood Cells (RBC). An ultrasonography was done for both patients with no significant findings. The worms pass mostly at early morning, i.e. voided urine, so the early morning urine sample collected is examined, tiny worms could be spotted by a naked eye 3 to $4 \mathrm{~mm}$ in length, Microscopic examination showed multiple larval stage of Musca domestica (Housefly)in the sample (Figures 1 \& 2).

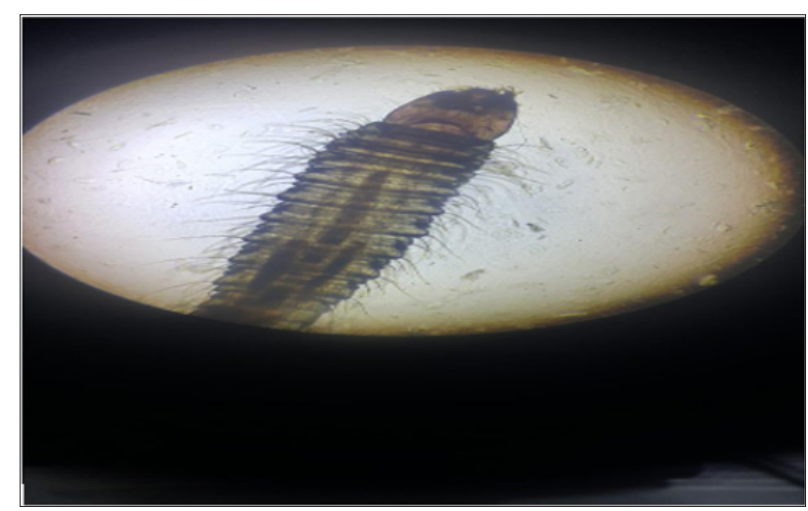

Figure 1:

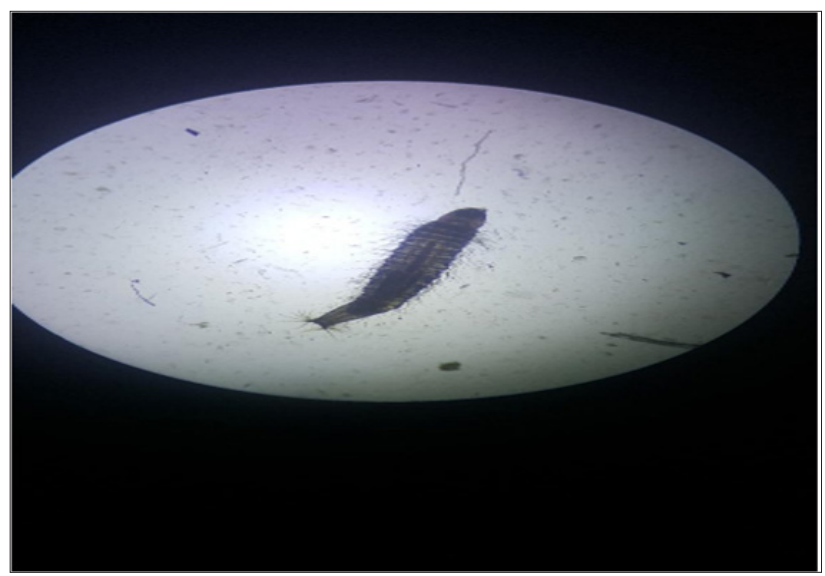

Figure 2:

In the detailed patients' history, it was stated that all of them used to let their underwear dry in the air. As a result, the Fly lies its egg on the fabric (underwear), the egg hatches in this kind of humid worm environment and passes easily into the bladder within few hours. Patients were asked to avoid drying their underwear outside or ironing it prior use, in this way the worm disappeared, simple antibiotics were employed to overcome a secondary bacterial infection. and adequate control of the fly propagation at home was attained.

\section{Discussion}

Myasis can be caused by many types of fly and might be widely distributed as cutaneous laryngeal, ocular urinary myiasis is very rare and can be caused by several agents, such as:

A. Larvae of Fannia scalaris [3] is the most frequent cause of urinary myiasis [6].

B. Lucilia sericata [7].

C. Eristalis tenax $[8,9]$.

D. Psychoda albipennis [10].

Accidental myiasis mostly happens when eggs contaminate the underwear or the fly deposits its eggs on the genital organ, the humidity and warmth let the eggs hatch and forming larva that can pass directly into the bladder, and void urine next morning. Urine myiasis is recorded mostly in women [11], since their short urethra may facilitate the passage of larva to the bladder. Urogenital myositis with different fly species has been reported in developing countries, especially in tropical/subtropical regions such as Malaysia, Algeria, Spain, Brazil and Iran [12], Saudi Arabia [13], India [14,15], Egypt [16] and Romania [17-20].

\section{Psychoda}

Clogmia (Telmatoscopus) albipunctata is a primitive Nematocera of the family Psychodidae, subfamily Psychodinae which are nonbiting moth flies known as drain, and bathroom or filter flies [13]. Clogmia albipunctata is cosmopolitan in distribution; the adult flies are often seen in moist places, especially bathrooms and toilets [14-16]. However, it is rarely encountered in humans with cases of urogenital myositis originating from $\mathrm{P}$.

\section{Albipennis}

P.albipennis 's body, not exceeding $12 \mathrm{~mm}$ in size, is covered with gray brown dense hairs. Adult flies, especially in humid toilets and bathrooms, leave their eggs on stones and other solid objects in moist and dim areas. The larvae are found especially in damp and dirty areas, deteriorating vegetables and fruits, garbage piles and sewage plants. There are four developmental stages of larvae of $P$. albipennis that emerged from the laying under suitable conditions. The larvae change their shirts three times to the pupa stage. In the urine of infested people, fourth period larvae of 4-8mm in size, which are scattered locally, can be seen [12]. To our knowledge this the first report of human urinary myiasis caused by Clogmia albipunctata in Egypt and the second case worldwide. This case draws the attention of urologists and laboratorians of the possibility of detecting dipteran flies' larvae in urine and urinary myiasis as an unusual cause of urinary tract infection.

\section{References}

1. (2003) Miller-Keane encyclopedia and dictionary of medicine, USA.

2. (2012) Farlex Partner Medical Dictionary, USA. 
3. Zumpt FKE (1965) Myiasis in man and animals in the old world. Butterworth.

4. Janovy J, Schmidt GD, Roberts LS (1996) Foundations of parasitology. In: Brown C (edn.), Spain.

5. John D, Petri W (2006) Markell and voge's medical parasitology. $\left(9^{\text {th }}\right.$ edn.), pp. 328-334.

6. Perez EC, Mouffok N (1999) Human urinary myiasis caused by Fannia canicularis (Diptera: Muscidae) larvae in Algeria. 28(11): 580-581.

7. Salimi M, Goodarzi D, Karimfar MH, Edalat H (2010) Human urogenital myiasis caused by Lucilia sericata (Diptera: Calliphoridae) and Wohlfahrtia magnifica (Diptera: Sarcophagidae) in Markazi Province of Iran. Iranian J Arthropod Borne Dis 4(1): 72-76.

8. Mumcuoglu I, Aral AG, Balaban N, Keles I (2005) Eristalis tenax as a cause of urinary myiasis. Scand J Infect Dis 37(11-12): 942-943.

9. Korzets Z, Bernheim J, Lengy J, Gold D (1993) Human urogenital myiasis due to Eristalis larva: An unusual cause of ureteric obstruction. Nephrol Dial Transplant 8(9): 874-876.

10. Güven E, Kar S, Doðan N, Karaer Z (2008) Urogenital myiasis caused by Psychoda albipennis in a woman. Turkey Parasitology Derg 32(2): 174176.

11. http://www.em-consulte.com/revue/LPM/28/11/table-des-matieres/
12. https://en.wikipedia.org/wiki/Microbiology

13. Wagner RF (2011) Europaea: Psychodidae. In: Jong H (edn.), Fauna Europaea: Diptera, Nematocera.

14. Wakid MH (2008) A laboratory-based study for first documented case of urinary myiasis caused by larvae of Megaselia scalaris (Diptera: Phoridae) in Saudi Arabia. Korean J Parasitol 46(1): 33-36.

15. Kamimura K, Arakawa RA (1986) Case report on urinary myiasis due to the moth fly, Telmatoscopus albipunctata. Med Vet Entomol 37: 161-162.

16. Hyun DY, Cain MP, Hnidy DE, Conway JH (2004) Urinary myiasis associated with ureteral stent placements. Pediatr Infect Dis J 23(2): 179.

17. Gopalakrishnan S, Srinivasan R, Saxena SK, Shanmugapriya J (2008) Myiasis in different types of carcinoma cases in southern India. Indian J Med Microbiol 26(2): 189-192.

18. Ayman AEB, Hosni KS, Yusuf AE (2014) Human urinary myiasis due to larvae of Clogmia (Telmatoscopus) albipunctata Williston (Diptera: Psychodidae) first report in Egypt. J Vector Borne Dis 51(3): 247-249.

19. (2012) Acta Microbiol Immunol Hung. 59(4): 46973.

20. Barabás HE, Sátán E, Mihály A (2012) Urogenital myiasis: A human case report. Acta Microbiol Immunol Hung 59(4): 469-473. 